This document is the accepted manuscript version of the following article:

Allegrini, J., Dorer, V., \& Carmeliet, J. (2012). Influence of the urban microclimate in street canyons on the energy demand for space cooling and heating of buildings.

Energy and Bui1dings, 55, 823-832. http://doi.org/10.1016/j.enbui1d.2012.10.013

This manuscript version is made available under the CC-BY-NC-ND 4.0 1icense

http://creativecommons.org/1icenses/by-nc-nd/4.0/

\title{
Influence of the urban microclimate in street canyons on the energy demand for space cooling and heating of buildings
}

\author{
Jonas Allegrini ${ }^{\mathrm{a},}$,, Viktor Dorer ${ }^{\mathrm{a}}$, Jan Carmeliet ${ }^{\mathrm{a}, \mathrm{b}}$ \\ ${ }^{a}$ Laboratory for Building Science and Technology \\ Swiss Federal Laboratories for Materials Science and Technology (Empa) \\ Überlandstrasse 129, 8600 Dübendorf, Switzerland \\ ${ }^{\mathrm{b}}$ Chair of Building Physics, Swiss Federal Institute of Technology Zurich (ETHZ), \\ Wolfgang-Pauli-Strasse 15, 8093 Zürich, Switzerland
}

\begin{abstract}
An important part of the world's energy is used for space cooling and heating of buildings. Its minimization has great energy saving potential. An important part of the heat exchange between buildings and the ambient surrounding is due to convective and radiative heat flows. In this study detailed building energy simulation (BES) is used to analyse the effect of neighbouring buildings on these heat flows and their influence on the space cooling and heating demand of buildings. BESs were conducted for stand-alone buildings and buildings in street canyon. This study demonstrates the importance of accounting for the urban microclimate for the prediction of the energy demand of buildings. With the proposed model most of the thermal effects of the urban microclimate can be captured and quantified on street canyon scale. Due to multiple reflections more solar and thermal radiation is absorbed at the façades of buildings in street canyons than at façades of stand-alone buildings. These effects cause higher surface temperatures in street canyons leading to higher space cooling and lower space heating demands. Other reasons are the lower convective heat transfer coefficients in street canyons, the reduced removal of heat from street canyons and the urban heat island effect.
\end{abstract}

\section{Keywords}

Building energy simulation, Energy demand, Space cooling, Space heating, Urban microclimate, Solar radiation

${ }^{*}$ Corresponding author: Jonas Allegrini, Empa Dübendorf, Ueberlandstrasse 129, 8600 Dübendorf, Switzerland. Tel.: +41 (0) 587654721 , Fax: +41 (0) 5876540 09, e-mail: jonas.allegrini@empa.ch 


\section{Introduction}

Residential and commercial buildings consume roughly respectively $25 \%$ and $15 \%$ of the final energy consumption in the EU, including all energy delivered to the final consumers (excluding deliveries for transformation and network losses). Heating represents almost $70 \%$ of the residential energy consumption [1]. Therefore there is a great energy saving potential by minimizing the energy demand for space cooling and heating of buildings. Today about $50 \%$ of the world population lives in urban areas, increasing to about $70 \%$ by 2050 [2]. The microclimate in urban areas differs significantly from the climate in rural areas. The air temperatures are higher due to the urban heat island (UHI) effect [3] and the wind speeds are lower due to wind sheltering by buildings. Measurements in London showed up to $7 \mathrm{~K}$ higher air temperatures at night-time in the city compared to measurements outside the city [4]. In Athens the mean heat island intensity exceeds $10 \mathrm{~K}$, which may double the energy demand for space cooling in buildings [5]. Global warming and respective heat waves $[6,7]$ may further increase the temperatures in urban areas and can reduce the potential for passive night ventilation cooling significantly in moderate climates. The UHI effect not only influences the energy demand for space cooling and heating of buildings, but has also a large impact on the thermal comfort and health of the people living in urban areas [8].

Building energy simulation (BES) models are commonly used to predict space cooling and heating demands of buildings [9]. Most BES models used today were developed for stand-alone buildings. The question remains if these BES simulations are adequate for predicting the energy demand of buildings in urban areas. It is known that the radiation exchange between neighbouring buildings has a major impact on the energy demand. Commonly only shadowing is modelled in BES. However, to correctly solve the energy balance, also multiple reflections of solar radiation between buildings and the long wave radiation exchange between them has to be accounted for. To model the convective heat transfer at the building envelope convective heat transfer coefficients (CHTC) are commonly used:

$$
\text { CHTC }=\frac{q_{c, w}}{T_{w}-T_{r e f}}
$$

where $C H T C$ is the convective heat transfer coefficient, $q_{c, w}$ is the convective heat flux normal to the wall, $T_{w}$ is the surface temperature at the wall and $T_{r e f}$ is a reference temperature. The CHTC relations used in BES are usually based on measurements at façades of stand-alone buildings (a literature overview of CHTCs used is given in [10]). Therefore, these CHTC correlations as a function of wind speed and surface temperature are not sufficiently correct for buildings in urban areas, since the flow field and as such also the convective heat transfer is strongly influenced by the neighbouring buildings. In built areas the CHTCs are also influenced by buoyancy effects caused by increased building surface temperatures, especially due to solar radiation. A third important urban aspect that has to be considered for a correct 
analysis of energy demand of buildings in urban areas is the UHI effect. Mostly meteorological data are not available for a specific urban area, or only for a very few locations. Therefore UHI models (e.g. [11, 12, 13, 14]) or additional temperature measurements are needed to account for the UHI effect. More recently city energy simulation models have been developed, which take the above mentioned urban phenomena into account. However, the urban phenomena are often too much simplified without resolving the physical mechanisms accurately at their relevant scale.

A number of studies have been conducted to investigate the influence of the urban microclimate on the energy demand of buildings. This influence is commonly modelled at different degrees of complexity. A first step is to account for the UHI effect by using meteorological data measured at a specific location instead of data from a meteorological station. Schneider et al. [15] found a significant change of the predicted energy demand by using different meteorological data for their simulations. Kolokotroni et al. [16] and Santamouris et al. [5] reported a significant reduction of the night ventilation potential for London and Athens due to the UHI effect. A second step consists in taking into account more correctly radiative heat fluxes. Stupka et al. [17] accounted for shadowing and reduced ground reflectance and found a lower heating demand with increasing density of the neighbourhood. Stromann et al. [18] found an increase of the total energy consumption of buildings due the effect of urban density on daylight availability and passive solar gains. The third step is to take the local air flow field into account. Bouyer et al. [19] coupled BES with CFD (computational fluid dynamics) simulations. The authors reported that the solar irradiance is the most important parameter for the energy demand of the studied building, followed by the convective fluxes. Ooka [20] proposed a similar coupling method for evaluating the energy demand and the thermal comfort inside buildings. It is known that for modelling the microclimate around a building accurately, effects at different scales have to be accounted for. These scales are the mesometeorological scale, the city scale, the city quarter scale, the street canyon scale and the building scale. The computational costs for taking all these scales into account in BES are still far too high. Therefore Rasheed [21] proposed a method to convert the complex geometry of a real urban area into a simplified geometry consisting of a regular grid of blocks. We can conclude that most of these studies focused only on the influence of one single aspect of the urban microclimate on energy demands or that urban microclimate physical mechanisms are strongly simplified.

The aim of this paper is to quantify the influence of the urban microclimate on the building energy demand for space cooling and heating using a more detailed approach including multiple radiative reflections, reduced convective heat losses and the UHI. For simplicity, a street canyon geometry is chosen as a case of a typical urban configuration of a city. The heat fluxes at the building façades are analysed to evaluate the influence of the specific long and shortwave radiative balance in urban areas on the surface temperature and their impact on the energy demand. Three building types with different building envelopes are considered. The first building type corresponds to a new well insulated building designed for a moderate European climate, the second to an old less insulated building and the third to a retrofitted 
building. These three building types represent a majority of buildings that can be found in urban areas in central Europe. The following approach was chosen for this study. Multizone BESs are conducted for different stand-alone buildings and for buildings located in street canyons with different aspect ratios. Daily UHI intensity schedules based on measured data for the Swiss city of Basel are used to account for the UHI effect. CHTC correlations derived for specific street canyon (SC) configurations and stand-alone (SA) buildings [22] are used to model the convective heat transfer at the building façades. The radiative exchange of long and shortwave radiation in the different street canyons are computed considering multiple reflections as implemented in the BES model. A study is conducted to quantify the sensitivity of the energy demand on different parameters such as UHI intensity, internal heat gain, ventilation concept and solar absorption coefficient of the building façade.

The structure of the paper is as follows. In section 2 the numerical model and the different building geometries and building types for the conducted simulations are presented. The resulting space cooling and heating demands for the different situations are analysed in section 3.1. Then the radiative fluxes and surface temperatures for two days in the summer period are analysed in more detail in section 3.2. In section 3.3 the results of the sensitivity study are given. In section 4 , the obtained results are discussed critically and in section 5 conclusions are drawn.

\section{Numerical model and simulation}

TRNSYS 17.0 [23] is used as code for the BES in this study. TRNSYS 17 is a transient 3D multizone BES software for single building. Simulations are conducted for a one year period with time steps of one hour. Heat conduction through the walls is modelled as 1D transient heat flow using wall transfer functions. TRNSYS 17 uses CHTC correlations to describe the convective heat transport at the outside surface of the building. In classical BES of SA (stand-alone) buildings, solar irradiation on façade elements is considered as a gain, and long wave radiation as a heat loss to the cold sky. In SC (street canyon) configurations, however, the solar direct and diffuse irradiation is characterized by multiple diffuse and specular reflections at the building surface. Similarly, multiple long wave reflections and radiative exchange with neighbouring building surfaces and the sky have to be considered. In TRNSYS 17, a 3D radiation model including multiple reflections is present, but which is only used for interior zones. Therefore, in this study, the street canyon between the buildings is modelled as an atrium within the building, but with an open ceiling to the sky. In this way, shadowing by the neighbouring buildings and the exchange of long wave and solar radiation between the different buildings can be accurately modelled. TRNSYS 17 determines which surfaces are sunlit and which are shaded, dependent on the position of the sun and the orientation of the studied building. At opaque surfaces a part of the direct solar radiation is absorbed and the remaining part is reflected in a diffuse way. Thus, specu- 
lar reflection of direct solar irradiation is not considered. If direct solar radiation hits a transparent surface (window), a part of the solar radiation is absorbed at the window panes, a second part is transmitted through the window into the building, and the rest is reflected diffusely. The sum of all diffuse shortwave radiation, consisting of diffuse solar radiation and the diffuse reflection of direct solar radiation, is distributed over all the surfaces in the street canyon (including a surface that represents the sky) using Gebhart factors [24, 25]. Gebhart factors are basically view factors, corrected in order to include the effect of multiple (diffuse) reflections:

$G_{i, k}=\left(I-F_{i, k} \sigma_{k}\right)^{-1} F_{i, k}\left(I-\sigma_{k}\right)$

where $G$ is the Gebhart factor matrix, $i$ is one of the surfaces that exchanges long wave radiation with surface $k, I$ is the identity matrix, $F$ is the view factor matrix and $\sigma$ the reflectivity.

The shortwave radiation fluxes in closed volumes are calculated as:

$Q_{s . k}=A_{k}\left(1-\alpha_{k}\right) I_{s, k}+\sum_{i=1}^{n} A_{i} G_{i, k} \alpha_{i} I_{s, i}$

where $n$ is the number of surfaces, $Q_{s}$ is the shortwave radiation flux, $A$ is the surface area, $\alpha$ is the surface albedo and $I_{s}$ is the solar radiation flux on surface $\mathrm{k}$.

The part of the diffuse shortwave radiation that is distributed onto transparent surfaces is again reflected, absorbed and transmitted through the window panes. As for the diffuse shortwave radiation, the long wave radiation in closed volumes is distributed using Gebhart factors:

$$
\begin{aligned}
& Q_{l, k}=A_{k} \varepsilon_{k} \sigma T_{k}^{4}-\sum_{i=1}^{n} A_{i} \varepsilon_{i} \sigma T_{i}^{4} G_{i, k} \\
& G_{i, k}=\left(I-F_{i, k} \sigma_{k}\right)^{-1} F_{i, k} \varepsilon_{k}
\end{aligned}
$$

where $Q_{l}$ is the long wave radiation flux, $\varepsilon$ is the emissivity, $\sigma$ is the Stefan-Boltzmann constant and $T$ is the surfaces temperatures.

For the sky a fictive sky temperature as a function of the ambient temperature, air humidity, cloudiness factor of the sky, and the local air pressure is used for the calculation of the long wave radiation. For surfaces that are not in a closed volume the long wave radiation to the sky and the environment is computed as follows:

$$
\begin{aligned}
& Q_{l, k}=A_{k} \varepsilon_{k} \sigma\left(T_{k}^{4}-T_{f s k y}^{4}\right) \\
& T_{f s k y}=\left(1-f_{s k y}\right) T_{a}+f_{s k y} T_{s k y}
\end{aligned}
$$


where $f_{\text {sky }}$ is the fraction of the sky seen by surface $\mathrm{k}, T_{a}$ is the ambient temperature and $T_{s k y}$ is the fictive sky temperature.

All surfaces are considered to be opaque for long wave radiation. Therefore no long wave radiation is transmitted through windows.

In this study the heating and cooling demand of three-storey office and residential buildings is analysed. BESs are performed for a stand-alone building in an open field and for the same building situated in an urban environment with a street canyon in front and behind the considered building. Street canyons with aspect ratios of $0.5,1$ and 2 are considered (aspect ratio H/W with $\mathrm{H}$ : height of the building, W: street canyon width). Figure 1 depicts the studied building surrounded by street canyons with an aspect ratio of 1 . Different orientations $\theta$ between $0^{\circ}$ (showing a north and a south façade) and $90^{\circ}$ (showing an east and a west façade) are used with steps of $15^{\circ}$. The orientation is defined as the angle between geographical north and the direction perpendicular to the street axes (see figure 1). Due to the symmetric arrangement of the buildings, we can limit to orientations between 0 and $90^{\circ}$. The building is assumed to be very long (110.5 m), corresponding in reality to a row of buildings, in order to minimize the effect of radiation on the lateral sides of the buildings. The height $\mathrm{H}$ (three-storey) and width $\mathrm{W}$ of the building is $13.5 \mathrm{~m}$. The lateral walls of the buildings are modelled adiabatic assuming that they are connected to other buildings. The studied street canyon building is surrounded by two other rows of buildings (figure 1), which have the same properties as the studied building. They are modelled adiabatic at their backside. The energy demands of these two buildings are not evaluated.

Three building types with different building envelopes are analysed. The first type, referred to as New Building (NewB), corresponds to a new well insulated building with a high glazing fraction of $50 \%$. The second building type, referred to as Old Building (OldB), is moderately insulated and has a small glazing fraction of 25\%, representing an old building as it can be found in existing urban areas in central Europe. The third building type represents a Retrofitted Building (RetroB). It has the same low glazing fraction as the old building, but is as well insulated as the new building. The U-values (and g-values for windows) of the different building envelopes are given in table 1.

Internal gains caused by lights, devices and persons and the occupancy schedules are set according to [26] for office and residential buildings (table 2). The gains given are related to the total floor area. The internal gains for offices buildings are used for the reference case, while the internal gains for residential buildings are used in Section 3.3, where the cooling demands of office and residential buildings are compared. The artificial light control is as follows: lights are on when the building is occupied and the solar radiation on the corresponding façade is $<70 \mathrm{~W} / \mathrm{m}^{2}$. External shading devices are closed when solar radiation on the corresponding façade is $>120 \mathrm{~W} / \mathrm{m}^{2}$ or there is direct radiation on the façade. The shading factor of the external shading devices is 0.8 . A mechanical ventilation system is used with a heat re- 
covery system with efficiency of $80 \%$. The ventilation rate at day-times is $30 \mathrm{~m}^{3} / \mathrm{h}$.person. At night-times an air change rate of $1 \mathrm{~h}^{-1}$ is assumed, but only if the building needs to be cooled. This rather low air change rate is chosen, because mechanical ventilation systems are usually dimensioned for demand air flow rates based on air quality criteria. Thus air change rates higher than $1 \mathrm{~h}^{-1}$ would require a larger ventilation system. This is usually not installed due to space and cost reasons. With natural ventilation different air change rates could be achieved. With the increased temperatures in urban areas, the natural ventilation rates would be reduced compared to the natural ventilation in rural areas.

Only space cooling and space heating demands are considered. The change in e.g. electricity demand due to changed artificial lighting demands, caused by shadowing, is not considered. The room air temperatures are controlled to remain between $21^{\circ} \mathrm{C}$ and $26^{\circ} \mathrm{C}$ by heating or cooling.

Due to lower local air speed in urban areas, the convective heat flow at façades is smaller for buildings in street canyons than for stand-alone buildings. Allegrini et al. [22] found that the space cooling demands for a building in a street canyon differ up to a factor of 1.8 depending on the used CHTC correlations. Mainly the geometry of the building, the presence of neighbouring buildings and buoyancy are found to be important influencing factors for convective heat transfer at the building surface. Therefore the choice of the correct CHTC correlations is an important aspect to account for when modelling the effect of urban microclimate. CHTC correlations from [22] are used, which were derived using 2D CFD simulations, assuming that the buildings and street canyons are infinite long, which corresponds to the long building assumption considered in this study. The CHTCs for elongated stand-alone buildings are found to be rather low compared to a stand-alone cubic building, which shows much higher CHTCs due to the 3D type of flow around the building [22]. For weather conditions with low wind speeds, the flow at building façades becomes mainly driven by buoyancy. Therefore CHTCs correlations for different temperature differences between the building façade and the air were established in [22] and used in this study.

Climatic data for the Swiss city of Basel are used as input for the BES. An UHI intensity approximation was developed based on measured data of the BUBBLE project [27]. A diurnal schedule of the temperature difference between the rural (here Basel-Binningen) and the urban (here Basel Spalenring) air temperature for each month was derived from the original data. For each hour of the day the temperature differences are averaged for a time period between 1.9.1994 and 31.12.2001. The temperature difference profiles are shown in figure 2. For the buildings in the urban environment, the temperature difference due to $\mathrm{UHI}$ is added to air temperature of the original meteorological station for each time step of the BESs. The UHI intensities for Basel are rather moderate compared with e.g. Athens where UHI intensities exceeding $10 \mathrm{~K}$ can be found [5]. The schedules show that the UHI intensity is higher at night-times than at day-times. 
Further it can be seen that the UHI intensity at night-times is more pronounced in summer and spring and less in winter and fall, while at day-times the opposite occurs.

\section{Results}

\subsection{Heating and cooling demands}

First, the space heating and cooling demands for the three building types in the street canyon (SC) configuration are compared with the demands for the stand-alone (SA) building. The aspect ratio of the street canyons is 1 . The building orientation in this study is $\theta=0^{\circ}$ (see figure 1) or the building façades are oriented north - south. For the stand-alone building air temperatures from the rural measurement station "Basel-Binningen" are used, while the air temperature in the SC configuration is corrected using the UHI intensity schedules as described above.

The space heating and cooling demands in figure 3 are normalized by the respective heating and cooling demand of the stand-alone New Building type $\left(56 \mathrm{MJ} / \mathrm{m}^{2} \mathrm{a}\right.$ and $1.7 \mathrm{MJ} / \mathrm{m}^{2}$ a respectively). Remark the difference in scales of the ordinate axes for heating and cooling demand. The results for the stand-alone building are compared with the same building in street canyon configuration for the three different building types (NewB, RetroB and OldB). Also the ratio in building energy demand between street canyon and stand-alone building configuration (SC/SA) is given.

We first discuss the heating and cooling demand in the SA configuration, which is considered as the reference configuration. The Old Building type shows a higher heating demand than the New and Retrofitted Buildings, which can be explained by the lower insulation quality of the Old Building type compared to the New and Retrofitted buildings. Remarkable is that the New and Retrofitted Buildings in SA configuration have approximately the same heating demand although their glazing fraction is quite different (respectively 50 and $25 \%$ ). For these types of buildings, we observed that the convective heat losses through the glazed areas are largely compensated by the solar gains through the glazing, and as a consequence both building types show the same heating demand. However, the higher glazing fraction of the New Building type leads to a higher cooling demand attributed to the higher solar gains through the glazing. Reduction of the glazing fraction, like for the Retro and Old Building, results in lower cooling demands. The Retrofitted Building, which is well insulated, shows the lowest cooling demand, which can be explained by the lower heat gains through the insulated walls.

Comparing SA and SC building configurations, we generally observe a reduction of heating demand and an important increase of the cooling demand for the buildings in SC configuration. Several urban phenomena explain this observation. A first reason is that solar radiation becomes entrapped inside street canyons, leading to higher building façade temperatures, and thus to lower heating and higher cooling demands in the SC configuration. The solar radiation is en- 
trapped in the following way: solar radiation heats up the sunlit urban surfaces that in return emit long wave radiation heating up other surfaces that are not sunlit. The solar radiation is then reflected multiple times between neighbouring buildings instead of being especially reflected back to the environment as is the case for the SA configuration. During summer the solar angles are higher and more solar radiation is entrapped compared to the winter. This means that the solar radiation entrapment has relatively a more important effect on the cooling than on the heating demand (in winter). A second reason for lower heating and higher cooling demands in a SC configuration is that at night-times the building façades cool less compared to a SA configuration, because the long wave radiation to the cold sky is partially blocked by the other buildings in a SC configuration. In winter, the reduction of long wave heat losses during night time leads to a lower heating demand in SC configuration compared to SA buildings, while in summer it leads to a higher cooling demand. A third reason for the difference in energy demand between SA and SC configuration is that in the SC configuration the convective heat losses and the removal of heat from the street canyon is much lower due to the lower local wind speeds inside the street canyons and the lower ventilation potential in a SC setting. A fourth reason is that due to the UHI phenomenon higher air temperatures occur in the city and thus also in the street canyons. The UHI effect thus further contributes to the reduction of the heating demand during winter and the increase of the cooling demand during summer. The UHI effect also decreases the night ventilation potential and possible night-time passive cooling, which will be analysed in more detail in Section 3.3.

Comparing the building heating demand in SA and SC building configurations in more detail, we observe that the heating demand of the Retrofitted Building in SC configuration is relatively more reduced (SC/SA ratio of 0.3) compared to the New Building type with higher glazing fraction (SC/SA ratio of 0.8). This difference can mainly be attributed to the balance between heat gains by radiation and the convective heat losses through the glazing. For the Retrofitted Building in SC configuration this balance is more positive towards lower heating demand than for the New Building, especially due to the increase in long wave radiative gains. For cooling, the relative difference between the energy demand in SC and SA configuration is very high up to SC/SA ratios of 10 . These differences are rather high due to the fact that the space cooling demand for stand-alone buildings is rather low for a climate like Basel. Therefore small changes in cooling demand may result in rather high relative differences.

Figure 4 shows the annual space cooling demands for the New Building type in SC and SA configuration. The results are given as function of the building orientation $\theta$ for different $\mathrm{SC}$ aspect ratios. Different floors of the building are considered: ground (1), middle (2) and top floor (3). In general the building cooling demand is higher for wide street canyons than for buildings in narrow street canyon configuration (or for the stand-alone building). Reason is that more solar radiation can enter wide street canyons and become entrapped inside. For all cases the space cooling demand is increasing from the first to the third floor. This can explained by the fact that the lower floors are for a longer time peri- 
od protected from the sun at day-time due to shadowing by neighbouring buildings. This shadowing effect is more important for narrow street canyons than wide street canyons. The first floor is additionally cooled by the contact to the cold soil underneath the building, while the upper floor level is additionally heated by the solar radiation absorbed by the building roof. For a building orientation $0^{\circ}$ (north - south façades) the cooling demand is lower than for $90^{\circ}$ (east west façades), with exception for the lower floors in the narrower street canyons $(\mathrm{H} / \mathrm{W}<1)$. In general, east - west façades $\left(90^{\circ}\right.$ orientation), are sunlit for a longer period during day-time leading to higher cooling demands. However, east - west façades of the lower floors in a narrow street canyon receive less direct solar radiation, because of the smaller solar angles during the morning and evening than for north - south façades during the afternoon, leading to lower cooling demands for this case.

\subsection{Radiative fluxes at the building surfaces}

In this section the radiative heat fluxes and surface temperatures are analysed in more detail for a $48 \mathrm{~h}$ time period during summer. We consider the SA and SC configuration for the New Building type with an orientation of $0^{\circ}$ (north south oriented façades).

In figure 5 the total solar radiation on the building façade (sum of the direct, diffuse and reflected radiation) is given for the north and south orientation. Results for the first building floor are given for street canyons with different aspect ratios. The first floor is selected, because here the influence of the neighbouring buildings on radiation is highest. As known, more solar radiation is absorbed on the south façade that is sunlit for a longer part of the day compared to the not sunlit north façade. The solar radiation on the south façade follows a classical daily pattern: increasing during the morning, reaching a peak in the afternoon and decreasing during the evening. The solar radiation on the north façade is on the contrary much more constant over day-time showing three smaller peaks, one in the morning, a second in the afternoon and a third in the evening. The peaks in the morning and evening are due to the direct solar radiation, while the peak in the afternoon is mainly due to the diffuse solar radiation. For the SC configuration with aspect ratio 0.5 , the afternoon peak becomes more important due to the reflection of the direct solar radiation hitting the south façade of the neighbouring buildings in the street canyon.

In wider street canyons (aspect ratio 0.5 ) more solar radiation is absorbed by building façade, because more solar radiation can enter the street canyon and becoming entrapped due to multiple reflections in wider street canyons. This explains why a façade of a stand-alone building receives less radiation, since in this case the façade does not receive additional radiation by reflection from other surrounding building façades. Exception is the case of the narrowest street canyon (aspect ratio of 2), where the solar radiation entering the street canyon is strongly reduced due to shadowing by 
neighbouring buildings. The solar radiation on a south façade is less sensitive to the SC aspect ratio, because here the direct solar radiation overpasses substantially the contribution by reflection from neighbouring building façades.

In figure 6, the total radiation, sum of shortwave solar and long wave radiation, is given for south and north façade of the first building floor. As for the solar radiation, more total radiation is absorbed on the south than on the north façade due to higher solar irradiation values. Comparing figures 6 and 5, we observe that the total radiation on the south façade is lower than the received solar radiation, while on the north façade these values are quite similar. A south façade heats up due to absorption of solar radiation and then emits long wave radiation to the cold sky and the neighbouring building façades, leading to lower total (net) values of radiation. During night time negative values of total radiation are observed, which can be explained by the long wave radiation to the cold sky. In the SC configuration, this effect is much reduced due to the blockage by neighbouring buildings. The blockage effect is more important for narrow than for wide street canyons. On both façades (but more pronounced on the north façade) the total radiation is much higher for buildings in SC than in SA configuration, since the SA building receives no long wave radiation reflected from the neighbouring buildings and radiates much more heat to the cold sky. The total radiation on façades increases with the width of the street canyons. Wider street canons receive more total radiation, leading to the higher entrance values and more entrapment of solar radiation.

In figure 7 the wall excess surface temperature (EST), defined as the difference between wall surface temperature and the ambient air temperature, is given for the north and south façades of the first building floor. In the case of a SA building, the ambient temperature represents the temperature at the meteorological station. In the SC case, it is the air temperature at a location close to the façade including the UHI and urban microclimate effect. The ESTs (excess surface temperatures) are generally positive with exception for the SA building at night-times. Comparing figure 6 and 7 , we observe that the ESTs follow the same tendencies as the total radiation, since the surface temperature is strongly linked to the net radiative heat flux. A second influencing factor is the convective heat transfer at the surface, but their influence is found to be much smaller than the influence of the radiation. For a more detailed analysis of the influence of the CHTC correlations on the space cooling demand of buildings we refer to [22]. The ESTs are for all cases higher on the south than on the north façade due to higher total net radiative heat fluxes on south façades. Especially on the north façade the ESTs are significantly higher for the SC buildings during the day. The lowest ESTs are found for the SA building. The highest ESTs are found at day-time for the widest street canyon, while at night-time the highest excess temperatures occur in the narrowest street canyon. In figure 8 the excess surface temperatures of the façade of the first floor for the New and Old Building are compared (SC aspect ratio of 1). The ESTs for the New Building are higher during the day and are lower during night than for the respective ESTs Old Building. This different behaviour is mainly caused by the higher thermal mass available in the Old Building façade leading to more damping of the extremes in EST. 


\subsection{Sensitivity study}

In this section, a sensitivity study of the space cooling demand is presented. We consider the influence of UHI effect, the use of night ventilation for passive cooling, the solar absorption coefficient of the façade and internal gains. For the internal gains we consider two cases: offices and residential buildings with lower gains (see table 2). For the solar absorption coefficients of the façades, we consider standard values of 0.5 for the reference case and values of 0.25 considering white paints. For the sensitivity study, the street canyon has an aspect ratio of 1 , an orientation of $0^{\circ}$ and the New building is considered. For the street canyons the results are normalized to the cooling demand of the case with UHI, night ventilation, solar absorption coefficients of 0.5 and internal gains of the office building (reference case). For the stand-alone building, the reference case is the one without UHI effect.

In figure 9 the results of this sensitivity study are given for the SC configuration (fig. 9a) and the SA building (fig. 9b). The cooling demand for the SC case decreases when no UHI effect is considered indicating the need for considering UHI for cooling demand simulations. For the SC configuration the space cooling increases significantly (with a factor of 2.7) when no passive cooling by night ventilation is considered. The effect of cooling by night ventilation is much more significant for the SA building, where the cooling demand increases relatively with a factor 9 when no night ventilation is used. The lower influence of nigh ventilation on the cooling demand in the SC case, compared to the SA setting, can be attributed to the higher air temperatures used for ventilation at night-time due to the UHI effect in the SC case. However, even in the SC case for Basel passive cooling by night ventilation significantly reduces the energy demands and has to be considered as a valuable approach to save energy for cooling. The application of white paints for the SA building leads to a small decrease in cooling demand (decrease of $18 \%$ ) due to the reduction of heat gains by increasing the reflection of radiation. For the SC building, the lower solar absorption coefficients $(0.25$ instead of 0.5$)$ of the façades have almost no impact on the space cooling demand. Reason is that the use of white paints leads to an increase of radiation entrapment due to the multiple reflections: the solar radiation becomes more often reflected between the buildings, until it's absorbed. For residential buildings showing lower internal gains less energy for cooling is needed both for street canyon and stand-alone building.

\section{Discussion}

The influence of the urban microclimate on the space cooling and space heating demand of buildings was investigated. This study was conducted for idealized stand-alone buildings and urban street canyons. Since the focus of this paper is more on the methodology and on the analysis of the importance of the different aspects of the microclimate, more realistic geometries like street intersections, buildings with pitched roofs or balconies etc. are not considered. However the same approach can be used for other (more complex) urban geometries. Urban street canyons were chosen as they are 
the most generic elements a city is composed of. Street canyons are also critical in terms of space cooling demand, due to the important effect of entrapment of the solar radiation and the wind sheltering by neighbouring buildings.

This study was conducted for the Swiss city of Basel. Cooling demand values will be quite different for cities in other (e.g. hotter) climate zones. However it is expected that the radiation exchange between urban surfaces, the UHI effect and the reduction in convective heat transfer are also here the most important phenomena to be considered in the assessment of the impact of urban microclimate on energy demand. In this paper the UHI intensity schedules were determined from measurements. No feedback mechanisms, such as heat gains / losses from building façades or building waste energy that influence the air temperature inside the street canyon were considered, nor the influence of these increased temperatures on the convective heat transfer and night ventilation cooling potential. An option to account for these feedback mechanisms is to directly couple BES and CFD. Here, for each BES time step, a CFD simulation computes the temperature field inside the street canyon and the corresponding CHTC values for that time step. The surface temperatures used in the CFD run are the temperatures obtained from the BES. The resulting air temperatures and CHTCs are then used for the next BES step. Such coupled simulations are however computationally expensive and therefore not yet practically feasible for annual building energy predictions.

We found that the exchange of long wave radiation with neighbouring buildings has a determining impact on the net radiative heat exchange at the building façade. An example with typical long wave radiation values is included here to illustrate the importance of this urban microclimatic phenomenon. The geometry considered for this example is a SA building and a building in SC configuration as given in figure 10. Typical surface temperatures and surface properties used in this example are given in table 3. For simplification, they are considered to be constant over the surface. The air temperature is $25^{\circ} \mathrm{C}$ and the temperature of the sky is $15^{\circ} \mathrm{C}$. The surfaces 4 and 6 , and the ground surface for the SC case, are assumed to be heated by the sun to temperatures higher than the ambient air temperature.

The long wave radiative flux $\dot{q}$ at the surfaces of the stand-alone building is calculated using the Stefan-Boltzmann law:

$\dot{q}=\sigma \varepsilon\left(0.5\left(T_{\text {Surf }}^{4}-T_{S k y}^{4}\right)+0.5\left(T_{\text {Surf }}^{4}-T_{G R}^{4}\right)\right)$

where $T_{\text {Surf }}$ the surface temperature and $T_{G R}$ is the temperature of the ground (here $25^{\circ} \mathrm{C}$ ). For the SC configuration the simplified approach by Glück [28] with Gebhart factors is applied to compute the long wave radiative heat fluxes. The radiative heat fluxes for the stand-alone building are lower respectively $114 \mathrm{~W} / \mathrm{m}^{2}$ for surface 4 and $54 \mathrm{~W} / \mathrm{m}^{2}$ for surface 6. The radiative heat fluxes for the SC configuration are respectively $87 \mathrm{~W} / \mathrm{m}^{2}$ for surface 4 and $7.6 \mathrm{~W} / \mathrm{m}^{2}$ for surface 6 . The SA building shows a total heat loss due to long wave radiation to the environment of $250 \mathrm{~kW}$, while this reduces to $141 \mathrm{~kW}$ for the SC building. This example with typical radiative heat fluxes at the façades shows that a building in a 
street canyon has only $56 \%$ of the long wave heat losses compared to a stand-alone building. This illustrates the importance of accounting for the long wave radiation exchange between neighbouring buildings in urban areas.

\section{Conclusion}

The space cooling and heating demands for a stand-alone building and buildings in an urban street canyon are compared for the moderate European climate of Basel (Switzerland). The three main influencing mechanisms of an urban microclimate are considered: (i) the radiation exchange between neighbouring buildings, (ii) the urban heat island (UHI) effect and (iii) the reduced convective heat transfer due to wind sheltering. This study was conducted for three different building types: a New, an Old and a Retrofitted Building.

It is found that the space cooling demand for all building types is higher and that the space heating demand is lower for buildings in a street canyon configuration than for the same stand-alone building. For the considered climate of Basel in Switzerland, the difference between rural and urban areas is higher for space cooling than for heating. All three mechanisms of the urban microclimate contribute to the observed trend. The most important mechanism is the radiation exchange between urban surfaces. In street canyons the net radiation on the building façades, being the sum of solar and long wave radiation including multiple reflections is higher than for façades of stand-alone buildings. Additionally for buildings in street canyons the long wave radiation to the cold sky, and possible cooling down of the façades, is partially blocked. Therefore higher façade surface temperatures can be found in urban than in rural areas. These higher temperatures of the building façades directly cause higher space cooling and lower space heating demands. The aspect ratio of the street canyon plays an important role: in wider street canyons more solar radiation may enter leading to more radiation entrapment. In narrow street canyons radiation entrance is decreased during day time due to shadowing, while during night time the blockage of long wave radiation to the sky increases. North oriented façades in a street canyon configuration receive much more short and long wave radiation compared to stand alone buildings due to the radiation entrapment. The urban heat island effect increases the air temperature in street canyons. Neglecting the UHI effect leads to an important underestimation of the cooling demand. The cooling potential by night ventilation is significantly reduced in urban areas by the urban heat island effect, but for moderate climates night ventilation is found to be an important measure to reduce the space cooling demand. Related to the radiation effects in street canyons, we found that the cooling demand increases with floor level of the building, and is higher for façades with East - West orientation. Use of white surfaces in street canyons is found to have only a minimal effect on the cooling demand, since the positive effect of higher reflections of radiation, white paints also lead to an increase of the radiation entrapment effect.

This study shows the importance of accounting for the local urban microclimate, when predicting the energy demands for buildings in urban areas. 


\section{Acknowledgments}

Funding by the Swiss Federal Office of Energy (SFOE) is gratefully acknowledged (Project Number: 154 143, Project Title: Urban climate and energy demand in buildings).

\section{References}

[1] European commission energy: Market observatory: Annual Report 2009. Available from http://ec.europa.eu/energy/observatory/annual_reports/annual_reports_en.htm (accessed 10.7.2012)

[2] UN, 2007. World Urbanization Prospects: The 2007 Revision Population Database. Available from http://esa.un.org/unup/ (accessed 10.7.2012)

[3] T.R.Oke. Boundary Layer Climates, second ed. Methuen, London,1987.

[4] R. Watkins, J. Palmer, M. Kolokotroni, P. Littlefair, The London Heat Island - results from summertime monitoring. Building Services Engineering Research \& Technology 23 (2) (2002) 97-106.

[5] M. Santamouris, N. Papanikolaou, I. Livada, I. Koronakis, C. Georgakis, A. Argiriou, D.N. Assimakopoulos, On the impact of urban climate on the energy consumption of buildings, Solar Energy 70 (3) (2001) 201-216.

[6] C. Schär, P.L. Vidale, D. Lüthi, C., Frei, C. Häberli, M.A. Liniger, C. Appenzeller, The role of increasing temperature variability in European summer heatwaves, Nature 427 (2004) 332-336.

[7] E.M. Fischer, C. Schär, Future changes in daily summer temperature variability: driving processes and role for temperature extremes, Climate Dynamics 33 (2009) 917-935.

[8] P. Moonen, T. Defraeye, V. Dorer, B. Blocken, J. Carmeliet, Urban Physics: Effect of the micro-climate on comfort, health and energy demand, Frontiers of Architectural Research, DOI: 10.1016/j.foar.2012.05.002 (2012).

[9] J.L.M. Hensen, R. Lamberts, Building Performance Simulation for Design and Operation, Spon Press, Oxon, 2011.

[10] T. Defraeye, B. Blocken, J. Carmeliet, Convective heat transfer coefficients for exterior building surfaces: Existing correlations and CFD modelling, Energy Conversion and Management 52 (2011) 512-522.

[11] P.A. Mirzaei, F. Haghighat, Approachs to study Urban Heat Island - Abilities and limitations, Building and Environment 45 (2010) 2192-2201.

[12] H. Swaid, M. Hoffman, Prediction of Urban Air Temperature Variations using the Analytical CTTC Model, Energy and Buildings 14 (1990) 313-324.

[13] E. Erell, T. Williamson, Comments on the correct specification of the analytical CTTC model for predicting the urban canopy layer temperature, Energy and Buildings 38 (2006) 1015-1021.

[14] M. Kolokotroni, M. Davies, B. Croxford, S. Bhuiyan, A. Mavrogianni, A validated methodology for the prediction of heating and cooling energy demand for buildings within the Urban Heat Island: Case-study of London, Solar Energy 84 (2010) 2246-2255.

[15] A. Schneider, A. Maas, Einfluss des Mikroklimas auf das energetische und thermische Verhalten von Gebäuden am Beispiel des Standortes Kassel, Bauphysik 32 (6) (2010) 348-358.

[16] M. Kolokotroni, I. Giannitsaris, R. Watkins, The effect of the London UHI on building summer cooling demand and night ventilation strategies, Solar Energy 80 (2006) 383-392. 
[17] R. Stupka, C. Kennedy, Impact of Neighborhood Density on Building Energy Demand and Potential Supply via the Urban Metabolism, ACEE Summer Study on Energy Efficiency in Buildings (2010) 239-252.

[18] J. Stromann-Andersen, P.A. Sattrup, The urban canyon and building use: Urban density versus daylight and passive solar gains, Energy and Buildings 43 (2011) 2011-2020.

[19] J. Bouyer, C. Inard, M. Musy, Microclimatic coupling as a solution to improve building energy simulation in an urban context, Energy and Buildings 43 (2011) 1549-1559.

[20] R. Ooka, Recent development of assessment tools for urban climate and heat-island investigation especially based on experience in Japan, International Journal of Climatology 27 (2007) 1919-1930.

[21] A. Rasheed, Multiscale Modelling of Urban Climate, PhD thesis 4531, EPFL, 2009.

[22] J. Allegrini, V. Dorer, J. Carmeliet, Analysis of convective heat transfer at building façades in street canyons and its influence on the prediction of space cooling demand in buildings, Journal of Wind Engineering \& Industrial Aerodynamics 104-106 (2012) 464-473.

[23] TRNSYS 17.0, Transient System Simulation Program, SEL, University of Wisconsin / TRANSSOLAR, Stuttgart, 2010 .

[24] B. Gebhart, Heat Transfer, second ed., McGraw-Hill, New York, 1971.

[25] B. Gebhart, Surface Temperature Calculations in Radiant Surroundings of Arbitrary Complexity - for Gray, Diffuse Radiation, International Journal of Heat and Mass Transfer 3 (4) (1961) 341-346.

[26] SIA 2024, Standard-Nutzungsbedingungen für die Energie- und Gebäudetechnik, SIA, Swiss Association of Engineers and Architects, Zürich, 2006.

[27] M.W. Rotach, R. Vogt, C. Bernhofer, E. Batchvarova, A. Christen, A. Clappier, B. Feddersen, S.-E. Gryning, G. Martucci, H. Mayer, V. Mitev, T.R. Oke, E. Parlow, H. Richner, M. Roth, Y.-A. Roulet, D. Ruffieux, J. A. Salmond, M. Schatzmann, J. A. Voogt, BUBBLE - an Urban Boundary Layer Meteorology Project, Theoretical and Applied Climatology 81 (2005) 231-226.

[28] B. Glück, Wärmetechnisches Raummodell, Gekoppelte Berechnungen und wärmephysiologische Untersuchungen, C.F. Müller Verlag, Heidelberg, 1997. 


\section{Figures}

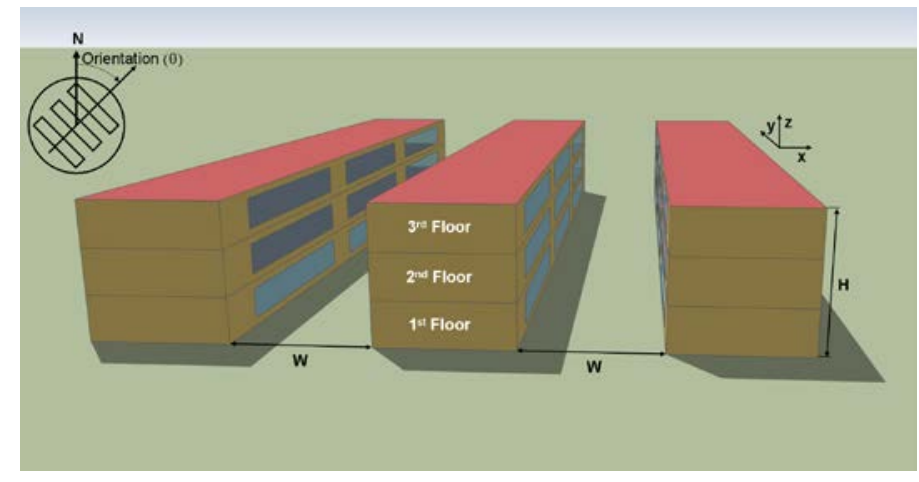

Figure 1: Studied building surrounded by street canyons with aspect ratios of $1(\mathrm{H} / \mathrm{W})$. The building of interest is the middle building.

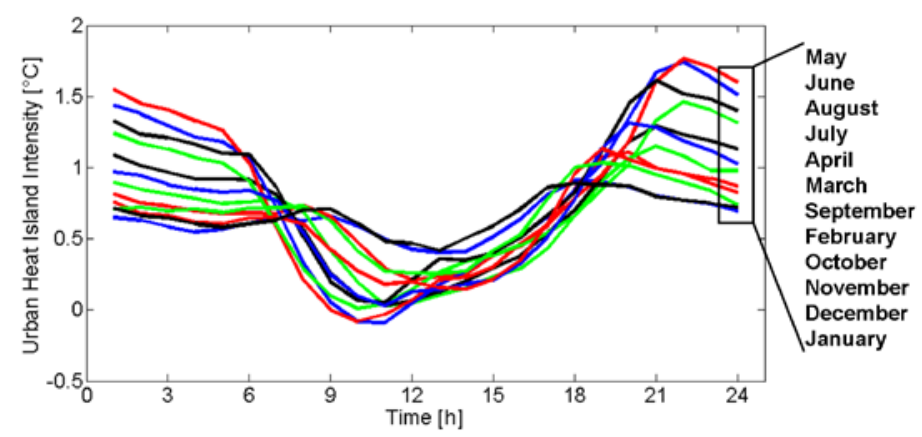

Figure 2: Average diurnal UHI intensity schedules for each month of a year.
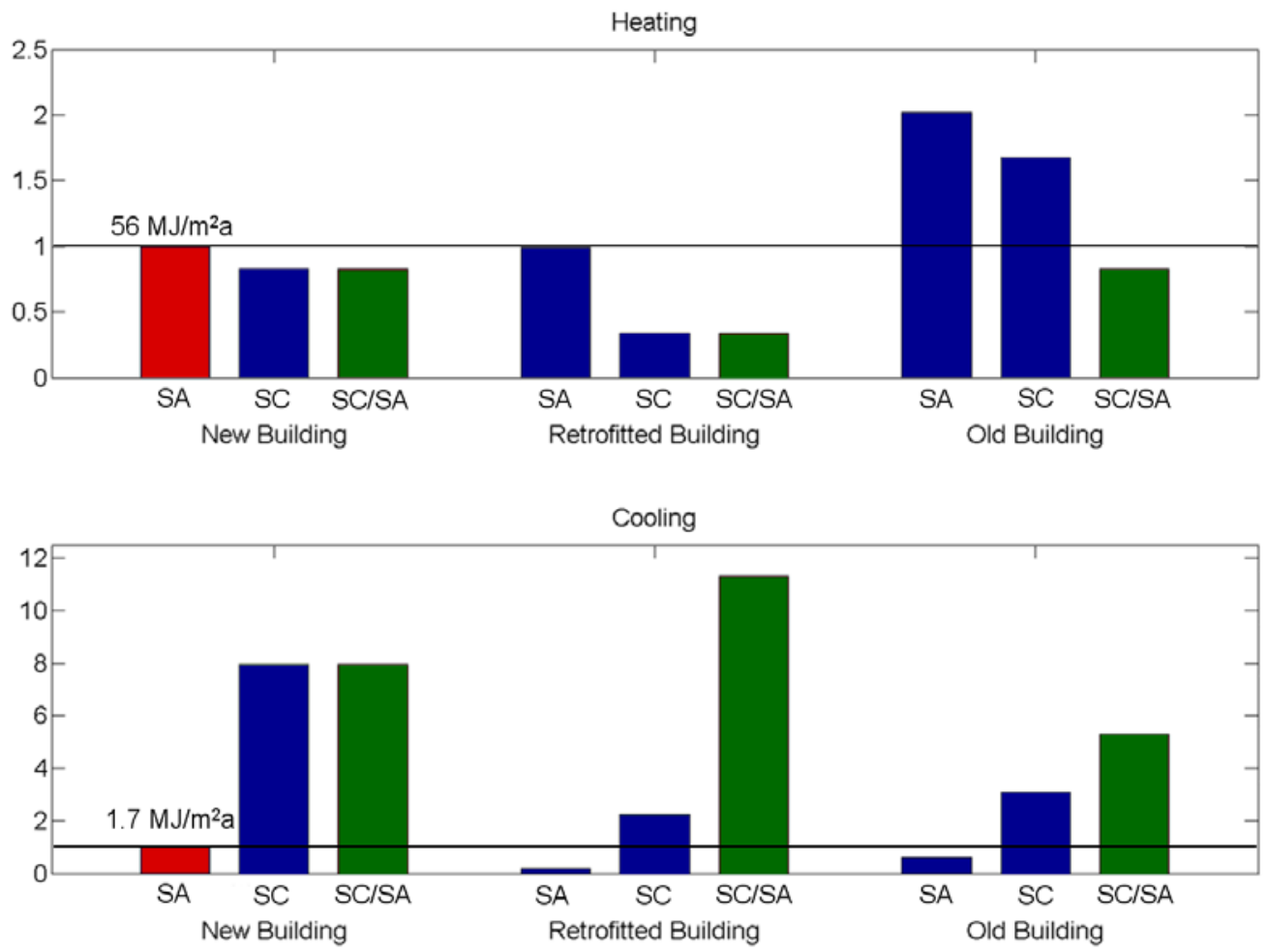

Figure 3: Annual space cooling and heating demands for three building types normalized by demands of the New standalone Building. Comparison between stand-alone buildings (SA) and buildings in street canyons (SC) with an aspect ratio of 1 . 

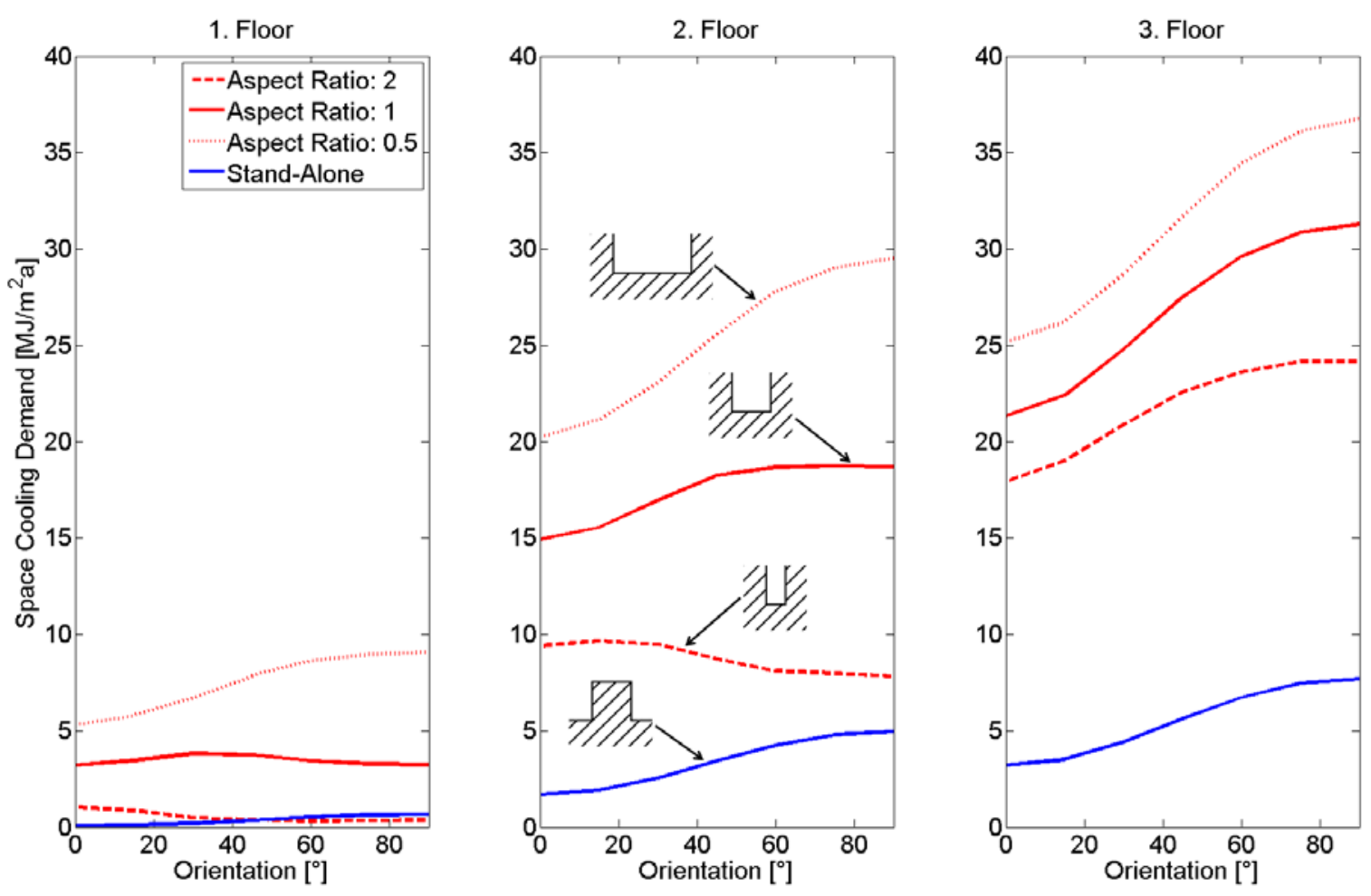

Figure 4: Annual space cooling demands for the three floors as a function of the street canyon orientation, for the three street canyon aspect ratios and the stand-alone building (New Building type).
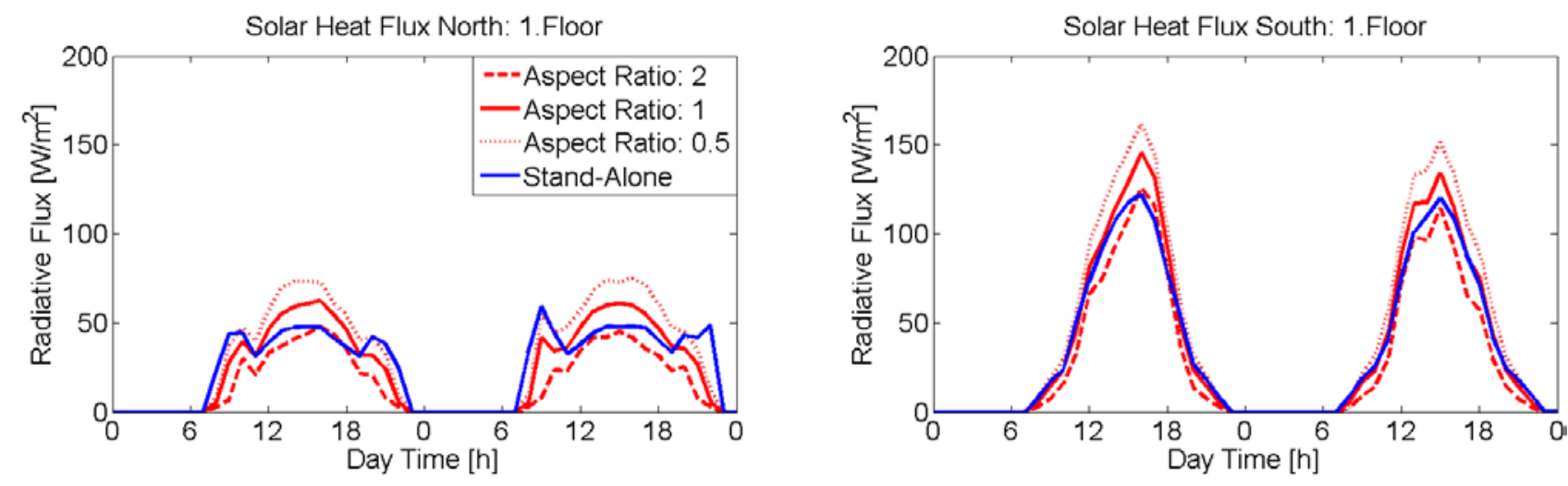

Figure 5: Absorbed solar radiation on the south and north façades of the first floor for a stand-alone building and buildings surrounded by street canyons with different aspect ratios $(0.5,1$ and 2$)$.
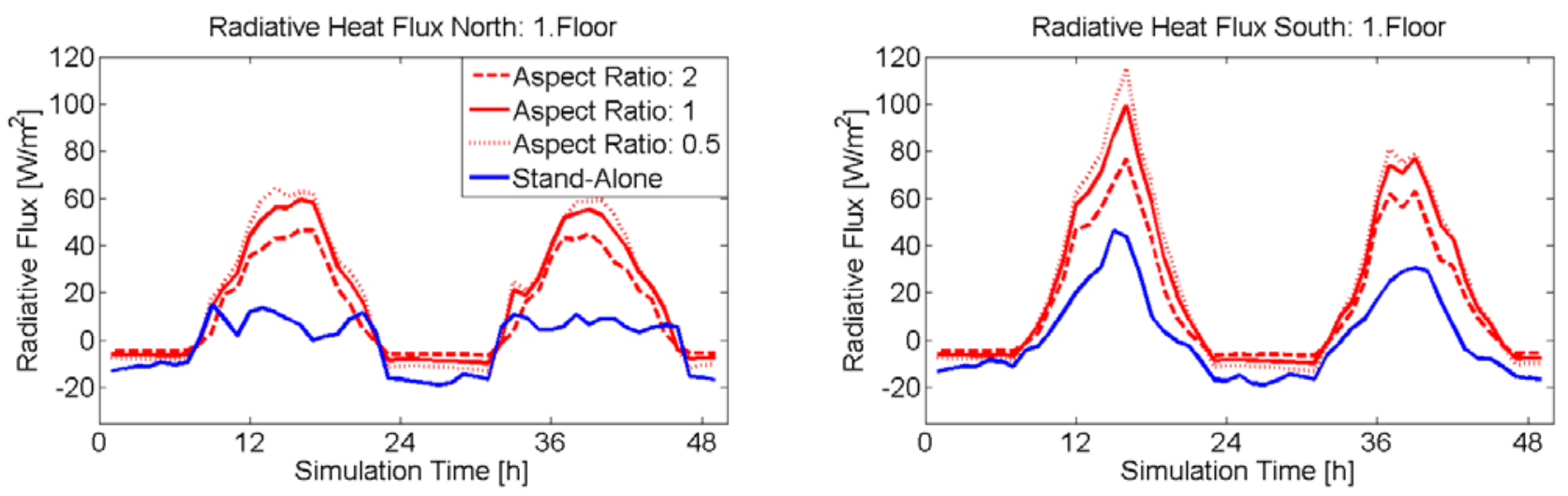

Figure 6: Absorbed radiation (solar plus long wave) on the south and north façades of the first floor for a stand-alone building and buildings surrounded by street canyons with different aspect ratios $(0.5,1$ and 2$)$. 

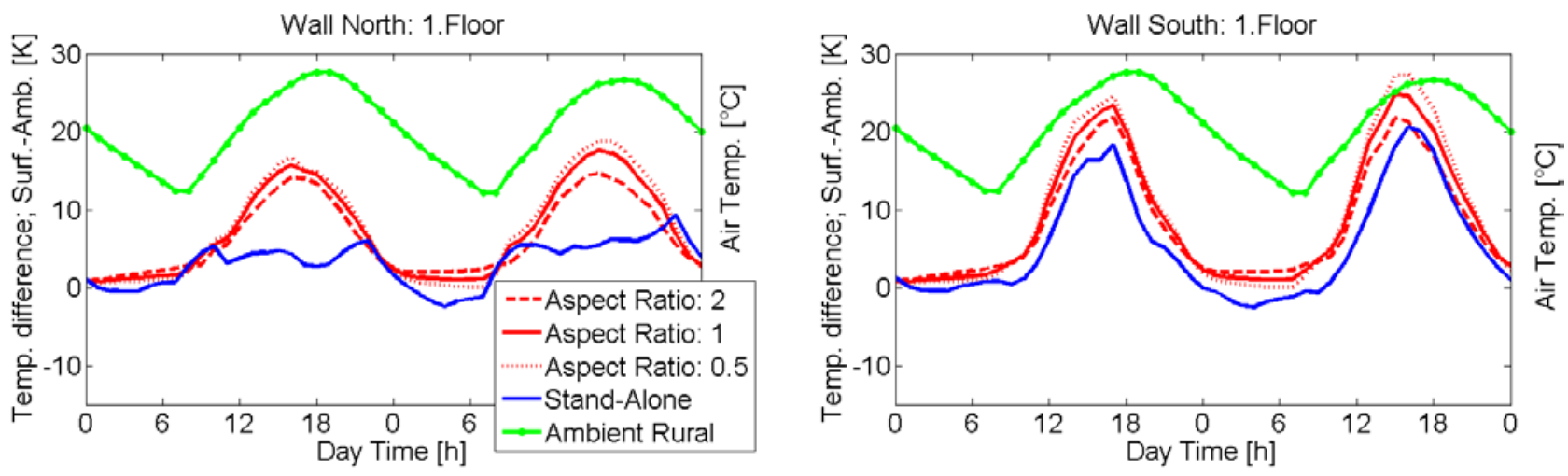

Figure 7: Differences between the wall surface temperature and the ambient air temperature for the north and south façades of the first floor for a stand-alone building and buildings surrounded by street canyons with different aspect ratios $(0.5,1$ and 2$)$.
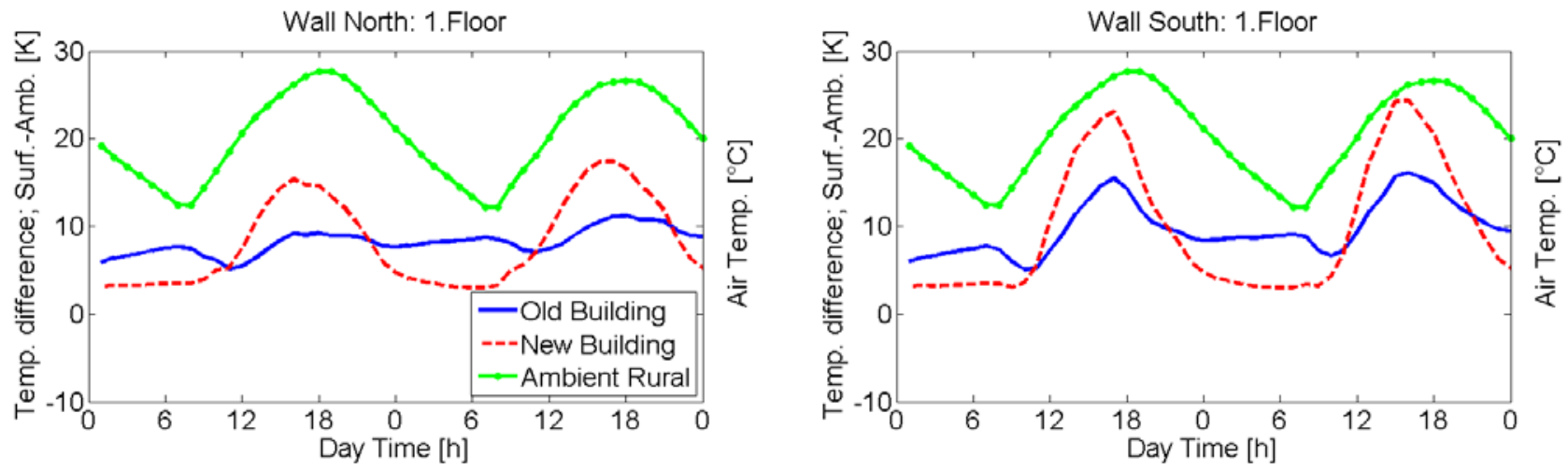

Figure 8: Differences between the wall surface temperature and ambient air temperature for the north and south façades of the first floor for the New and the Old Building with an aspect ratio of 1.

a

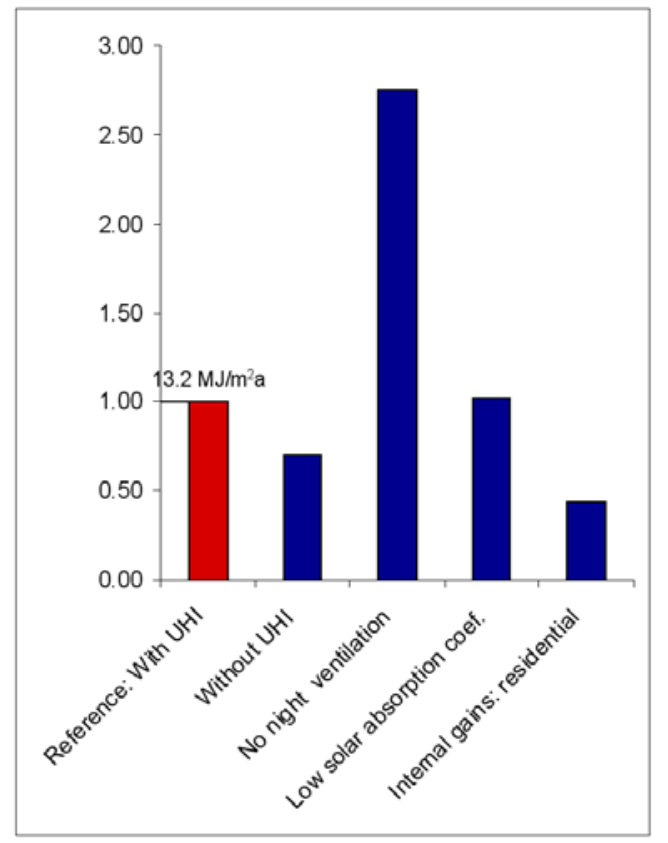

b

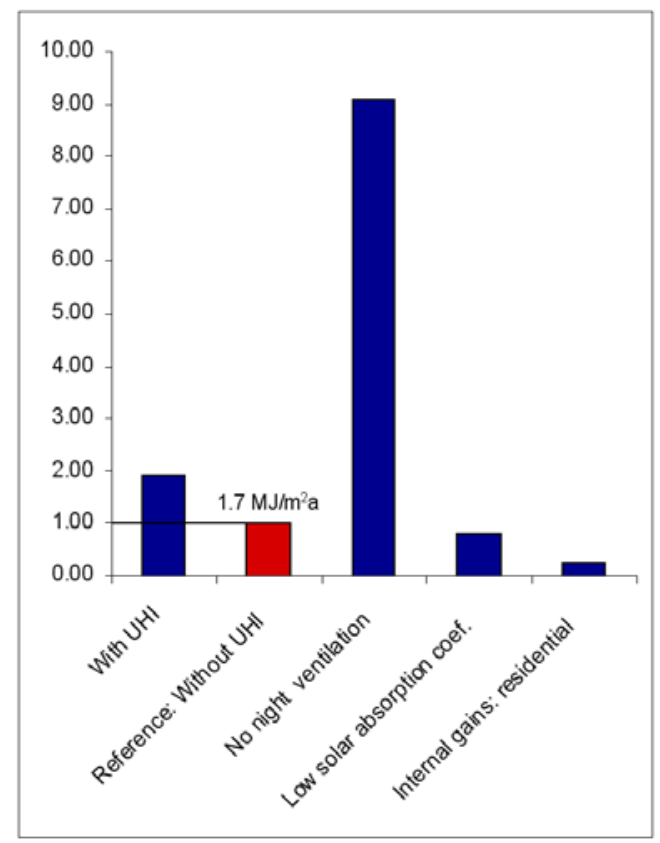

Figure 9: Annual space cooling demand for the New Building type and an orientation of $0^{\circ}$. (a) Building surrounded by street canyons with an aspect ratio of 1, normalized by the case with UHI intensity; (b) stand-alone building, normalized by the case without UHI intensity. 

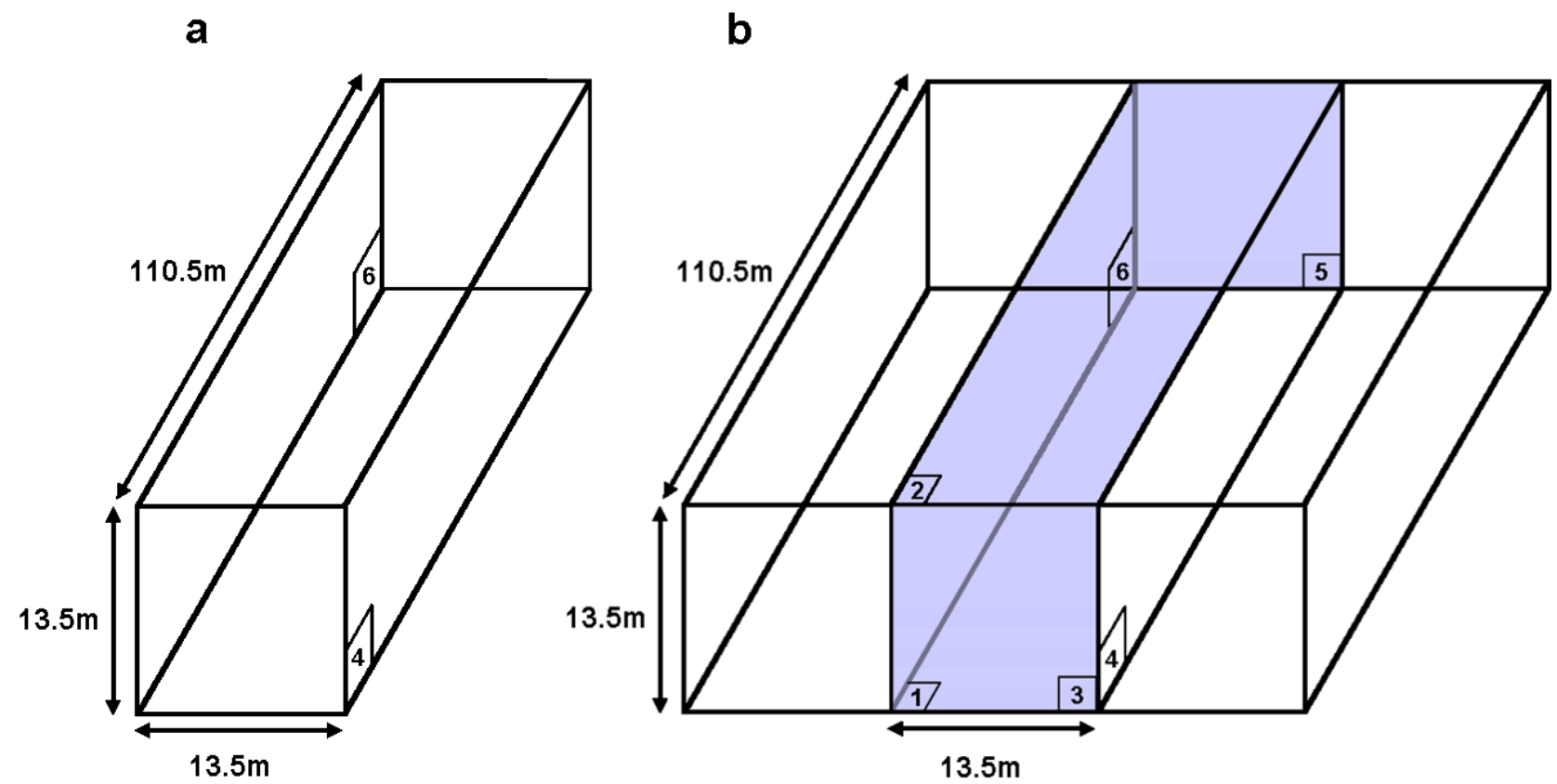

Figure 10: Stand-alone building (a) and the street canyon (b) geometries of the radiation example. 
Tables

\begin{tabular}{|c|c|c|c|c|c|}
\hline & & Materials & Thickness [m] & $\mathrm{U}$-value $\left[\mathrm{W} / \mathrm{m}^{2} \mathrm{~K}\right]$ & g-value [-] \\
\hline \multirow[t]{4}{*}{ New Building } & Walls & Plaster, Brick, Insulation & 0.372 & 0.259 & \\
\hline & Roof & Plaster, Concrete, Insulation, Gravel & 0.53 & 0.151 & \\
\hline & Ground floor & Carpet, Screed, Insulation, Concrete & 0.376 & 0.295 & \\
\hline & Windows & & & 1.4 & 0.589 \\
\hline \multirow[t]{4}{*}{ Old Building } & Walls & Plaster, Brick, Insulation & 0.340 & 0.497 & \\
\hline & Roof & Plaster, Concrete, Insulation, Gravel & 0.305 & 0.511 & \\
\hline & Ground floor & Carpet, Screed, Insulation, Concrete & 0.376 & 0.295 & \\
\hline & Windows & & & 2.83 & 0.755 \\
\hline
\end{tabular}

Table 1: Building envelope properties.

\begin{tabular}{lllll}
\hline & & Persons $\left[\mathrm{W} / \mathrm{m}^{2}\right]$ & Devices $\left[\mathrm{W} / \mathrm{m}^{2}\right]$ & Lights $\left[\mathrm{W} / \mathrm{m}^{2}\right]$ \\
\hline \multirow{2}{*}{ Office } & radiative & 3 & 2 & 6.25 \\
\cline { 2 - 5 } & convective & 4.2 & 8 & 6.25 \\
\hline Residential & radiative & 0.6 & 0.4 & 6.58 \\
\cline { 2 - 5 } & convective & 0.9 & 1.6 & 2.82 \\
\hline
\end{tabular}

Table 2: Internal gains.

\begin{tabular}{lll}
\hline Surface & Temperature $\left[{ }^{\circ} \mathrm{C}\right]$ & Emissivity [-] \\
\hline 1 & 28 & 0.9 \\
\hline 2 & 15 & 1 \\
\hline 3 & 25 & 0.9 \\
\hline 4 & 40 & 0.9 \\
\hline 5 & 25 & 0.9 \\
\hline 6 & 30 & 0.9
\end{tabular}

Table 3: Surface temperatures and long wave emissivities of the surfaces in figure 10. 